\title{
Prevalence of Coinfection with Malaria and HIV among Children in Yaoundé, Cameroon: A Cross-Sectional Survey Performed in Three Communities in Yaoundé
}

\author{
Tebit E. Kwenti1,2,3, Emilienne Edo², Besong S. Ayuk ${ }^{3}$, Tayong D. B. Kwenti ${ }^{1}$ \\ ${ }^{1}$ Department of Medical Laboratory Sciences, University of Buea, Buea, Cameroon \\ ${ }^{2}$ Department of Microbiology and Parasitology, University of Buea, Buea, Cameroon \\ ${ }^{3}$ Regional Hospital of Buea, Buea, Cameroon \\ Email: kwentitebit@yahoo.com, emmakwen@gmail.com
}

How to cite this paper: Kwenti, T.E., Edo, E., Ayuk, B.S. and Kwenti, T.D.B. (2017) Prevalence of Coinfection with Malaria and HIV among Children in Yaoundé, Cameroon: A Cross-Sectional Survey Performed in Three Communities in Yaoundé. Yangtze Medicine, 1, 178-188.

https://doi.org/10.4236/ym.2017.13018

Received: July 28, 2017

Accepted: September 24, 2017

Published: September 27, 2017

Copyright (c) 2017 by authors and Scientific Research Publishing Inc. This work is licensed under the Creative Commons Attribution International License (CC BY 4.0).

http://creativecommons.org/licenses/by/4.0/

(c) (i) Open Access

\begin{abstract}
Background: Malaria and HIV are endemic in Cameroon. But data on the prevalence of coinfection with malaria and HIV in Cameroonian children are essentially absent. This study was aimed at determining the prevalence of coinfection with malaria and HIV among children in Yaoundé, so as to advice control policies. Methods: In a cross-sectional survey, children ( $\leq 15$ years) were recruited from 3 communities in Yaoundé namely: Efoulan, Biyem-assi and Cité-verte. A semi-structured questionnaire was used to collect demographic data. Participants were screened for malaria parasites by the examination of Giemsa-stained blood films meanwhile participants were screened for HIV following Cameroon's national algorithm. The Pearson's chi-square test was performed as part of the statistical analyses. Statistical significance was set at $\mathrm{p}<0.05$. Result: Three hundred and ten (310) children took part in the study. The mean age $( \pm \mathrm{SD})$ of the participants was $75.64( \pm 63.23)$ months and a majority of them were males (56.1\%). The prevalence was $19.7 \%, 4.8 \%$ and $1.2 \%$ for malaria, HIV, and coinfection with malaria and HIV respectively. The prevalence of malaria was associated with age $(\mathrm{p}=0.009)$ meanwhile the prevalence of HIV was associated with study site $(\mathrm{p}=0.024)$. Plasmodium falciparum was the only species identified as causing malaria in the target population. Conclusion: A substantial prevalence of malaria, HIV and coinfection with malaria and HIV was observed in this study. Efforts should be strengthened to control and eventually eliminate these diseases in the target population.
\end{abstract}




\section{Keywords}

Malaria, HIV, Coinfection, Plasmodium falciparum, Prevalence, Children, Yaoundé, Cameroon

\section{Introduction}

Malaria is a mosquito-borne infectious disease affecting humans and other animals. Globally there were an estimated 212 million cases of malaria and 429,000 deaths attributed to malaria in 2015 [1]. The incidence rate of malaria is estimated to have decreased by $41 \%$ globally between 2000 and 2015, meanwhile the malaria mortality rates have declined by $62 \%$ within the same timeframe [1]. The majority of cases and deaths attributed to malaria occur in sub-Saharan Africa (SSA) [1]. Although there has been a decline in malaria recently, malaria still remains a significant cause of morbidity and mortality in SSA, claiming the live of a child every 2 minutes [2]. In Cameroon, malaria is a major cause of morbidity and mortality among children [3] [4] [5]. Malaria is caused by parasitic protozoans of the genus Plasmodium. Five species are known to cause disease in humans namely; Plasmodium ovale, $P$. malariae, $P$. knowlesi, $P$. vivax, and $P$. falciparum, with the latter being the most virulent species accounting for the majority of cases and deaths attributed to malaria. Like in other SSA countries, $P$. falciparum is the predominant species in Cameroon [4] [6] [7].

SSA also has the highest burden of the human immunodeficiency virus (HIV). In 2014, there were 25.8 million people living with HIV/AIDS (PLWHA) in SSA [8], accounting for approximately $70 \%$ of the global total. In Cameroon the overall prevalence of HIV is estimated at 4.5\% [9]. There are about 39,000 children $(<14$ years) living with HIV in Cameroon and about 310,000 children orphaned due to AIDS [9]. HIV in Cameroon affects typically the poor and less privileged [10].

Because of the presence of all the factors favouring transmission in SSA including poverty, malaria and HIV are common in the region. Due to their overlapping distribution, coinfection with malaria and HIV is therefore bound to be common in the area. Coinfection with malaria and HIV is thought to have a synergistic effect, with studies reporting that repeated infection with malaria leads to a more rapid decline in $\mathrm{CD} 4^{+} \mathrm{T}$ cells overtime, meanwhile malaria coinfection with HIV results in more episodes of symptomatic malaria [11], and more episodes of severe or complicated malaria including death in both children and adults [12] [13] [14] [15] [16]. The risk of severe anaemia is also higher in HIV patients coinfected with malaria compared to HIV patients without malaria [17] [18]. In Cameroon, the prevalence of coinfection with malaria and HIV among adolescence and adults has been reported to range between $2.24 \%$ to $29.4 \%$ [15] [16] [19]. But studies reporting the prevalence of coinfection with malaria and HIV in children are very limited in the country. 
This study was therefore designed to determine the prevalence of coinfection with malaria and HIV among children in Yaoundé, in order to generate data for clinico-epidemiological purposes which will improve on the control of both diseases in the country.

\section{Materials and Methods}

\subsection{Study Area}

This study was performed in Yaoundé in the Centre region (Figure 1). Yaoundé $\left(3^{\circ} 52^{\prime} \mathrm{N} 11^{\circ} 31^{\prime} \mathrm{E}\right)$ with an average elevation of $750 \mathrm{~m}$, is the capital of Cameroon. With a population of roughly 2.5 million, Yaoundé is second only to Douala as the largest city in Cameroon [20]. Yaoundé is a very diverse city with people from different works of life and is home to most of the administrative structures in the country. The climate of Yaoundé is tropical with 2 rainy (March to June, September to November) and 2 dry seasons (December to February, July-August). Malaria transmission in Yaoundé is holoendemic and seasonal with Anopheles gambiae as the principle vector [21]. According to hospital records, peak malaria transmission occurs at the beginning of the rainy seasons. The prevalence of malaria in the general population of Yaoundé is estimated at 35\% [22] meanwhile the prevalence of HIV is estimated at $8.3 \%$ [10].

\subsection{Study Design and Setting}

This was a cross-sectional study performed between May and June 2017, involving children randomly selected from 3 communities in Yaoundé.

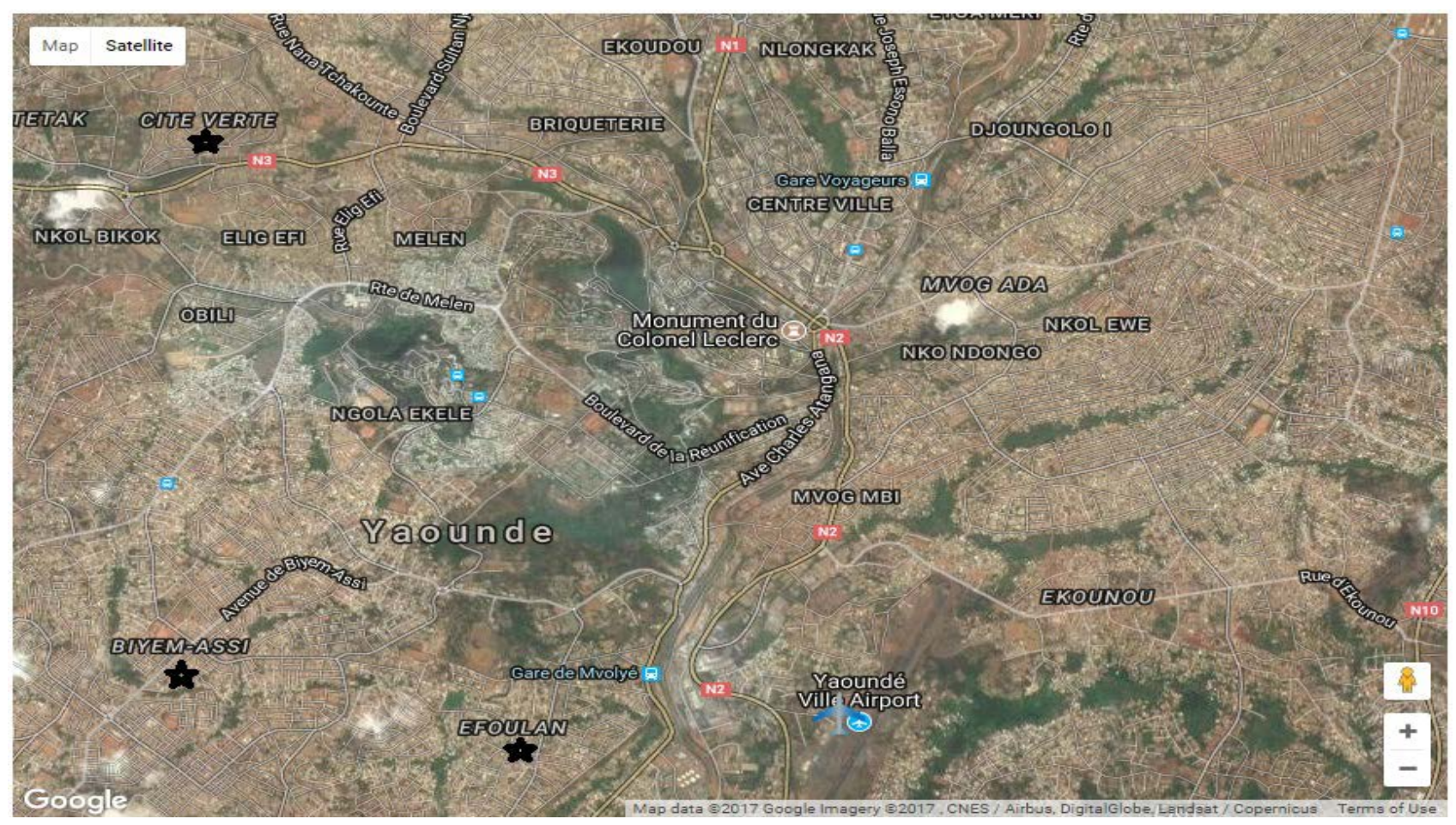

Figure 1. Map of Yaoundé. The study sites are delineated. 


\subsection{Sample Size Estimation}

The sample size was estimated using the formula for sample size calculation described by Swinscow [23] as follows;

$$
\begin{aligned}
& n=\frac{Z^{2} \times p(1-p)}{e^{2}} \\
& Z=1.96 \\
& p=\text { prevalence of malaria in children in Cameroon }=17.6 \%[7] . \\
& e=\text { error rate }=0.05 \\
& n=\frac{1.96^{2} \times 0.176(1-0.176)}{0.05^{2}}=222.9
\end{aligned}
$$

Thus we recruited 310 participants to adjust for possible loss of samples.

\subsection{Sampling Technique}

Two stage sampling was done. In the first stage, 3 communities were randomly selected in Yaoundé including: Efoulan, Biyem-assi, and Cité-verte (Figure 1). In the second stage, houses in the communities were randomly selected and children aged 15 years and below within selected houses were enrolled.

\subsection{Study Population}

Children ( $\leq 15$ years) of both sexes were eligible to participate in the study. The participants were recruited from 3 communities in Yaoundé namely: Efoulan, Biyem-assi and Cité-verte. Written informed consent was obtained from the parents or guidance of the children after explaining to them the study protocol and objectives. Excluded from the study were children not residing in the selected communities as well as those on any antimalarial drug 2 weeks prior to the study commencing.

\subsection{Ethical Consideration}

Authorization to carry out this research was obtained from the Faculty of Health Sciences, University of Buea, and from the Delegation of Public Health, Yaoundé, Center region. Written informed consent was obtained from all participants prior to their inclusion.

\subsection{Data Collection}

A semi-structured questionnaire was used to collect demographic characteristics (age, gender, etc.). The questionnaire was administered to the parents or guidance of the children by members of the research team.

\subsection{Sample Collection}

About $3 \mathrm{ml}$ of blood was collected from the children into EDTA anticoagulated tubes following antiseptic techniques. The blood was used to perform the complete blood count, preparation of blood films as well as screening for HIV. 


\subsection{Laboratory Analysis}

\subsubsection{Performance of Complete Blood Count (CBC)}

CBC was performed using the Mindray ${ }^{\circledR}$ Auto haematology analyzer (BC-2800, Shenzhen Mindray Bio-Medical Electronics Co., Ltd.). The white blood cell counts were obtained from the $\mathrm{CBC}$ results and used in the estimation of the parasite density.

\subsubsection{Detection of Malaria Parasite}

The prepared blood films were air-dried and stained with 10\% Giemsa (1 in 20 dilutions) for 25 - 30 minutes [24]. The blood films were read by two expert microscopists who were blinded from the results of the other. In the case of any discrepancy with the results obtained by the two microscopists, a third was brought in and the results he gave were considered as final. At least 200 fields were screened for malaria parasite using the 100X (oil immersion) objective and where parasites were seen, they were counted until $500 \mathrm{WBC}$ were reached. The slides were only declared negative after counting to 2500 WBC. Malaria parasite density was estimated by dividing the parasites counted by $500 \mathrm{WBC}$ and then multiplied by the actual WBC count of the participant to give numbers in parasite per $\mu \mathrm{l}[7]$.

\subsubsection{Screening for HIV}

HIV screening was done in accordance with the Cameroon's national algorithm for HIV screening by detecting anti-HIV antibodies [25]. Briefly, a first line rapid test was used and if positive, a second line test was used to confirm the result as well as determine the HIV type. Where the first line test was positive and the second line test was negative, a third line test was brought in. In this study, the first line test used was Determine ${ }^{\text {Tx }}$ HIV (Abbott Laboratories, Abbott Park, IL, USA), the second line test was First Response ${ }^{\circledR}$ (Kachigam, India) and the third line test was Immuno-Comb ${ }^{\circledR}$ (Orgenics Ltd., Israel).

\subsection{Statistical Analyses}

Data collected was entered into Excel spreadsheet and analyzed using Stata ${ }^{\circledR}$ version 12.1 (StataCorp LP) statistical package and group comparisons were performed using the Pearson's Chi-square test. Statistical significance was set at $\mathrm{p} \leq$ 0.05 .

\section{Results}

Three hundred and ten (310) participants successfully took part in the study. Their ages ranged between 0 and 180 months, with mean $( \pm S D)=75.64( \pm 63.23)$ months. Among them were 136 (43.9\%) females and 174 (56.1\%) males (Table 1).

Among the 310 participants, 61 were positive for malaria giving a prevalence of $19.7 \%$ (95\% CI: 15.4 - 24.6). Malaria prevalence was associated with age ( $\mathrm{p}=$ $0.01)$ but not with gender $(\mathrm{p}=0.427)$ nor study site $(\mathrm{p}=0.337)$ (Table 2$)$. Plas- 
modium falciparum was the only species identified. There was no mixed infection with the other Plasmodium species.

Among the 310 participants, 15 were positive for HIV giving a prevalence of 4.8\% (95\% CI: 2.7 - 7.9). Fourteen (93.3 \%) of the cases were HIV type 1 and 1 (6.7\%) HIV type 2. HIV prevalence was associated with study site $(\mathrm{p}=0.024)$ but not with age $(\mathrm{p}=0.562)$ nor gender $(\mathrm{p}=0.823)$ (Table 2$)$.

Coinfection with malaria and HIV was observed in 4 of the 310 participants giving a prevalence of 1.2\% (95\% CI: 0.4 - 3.3) (Figure 2).

Table 1. The distribution of the participants with respect to age, gender and study site.

\begin{tabular}{|c|c|c|c|c|c|c|}
\hline & \multirow{2}{*}{ Study Site } & & \multicolumn{3}{|c|}{ Age (Month) } & \multirow{2}{*}{ Tota } \\
\hline & & & $<60$ & $60-119$ & $120+$ & \\
\hline \multirow{3}{*}{ Biyem-assi } & \multirow{2}{*}{ Gender } & Female & 18 & 11 & 13 & 42 \\
\hline & & Male & 32 & 10 & 15 & 57 \\
\hline & \multicolumn{2}{|c|}{ Total } & 50 & 21 & 28 & 99 \\
\hline \multirow{3}{*}{ Cite-verte } & \multirow{3}{*}{ Gender } & Female & 21 & 12 & 26 & 59 \\
\hline & & Male & 30 & 21 & 20 & 71 \\
\hline & & Total & 51 & 33 & 46 & 130 \\
\hline \multirow{3}{*}{ Efoulan } & \multirow{2}{*}{ Gender } & Female & 13 & 8 & 14 & 35 \\
\hline & & Male & 30 & 10 & 6 & 46 \\
\hline & \multicolumn{2}{|c|}{ Total } & 43 & 18 & 20 & 81 \\
\hline \multirow{3}{*}{ Total } & \multirow{2}{*}{ Gender } & Female & 52 & 31 & 53 & 136 \\
\hline & & Male & 92 & 41 & 41 & 174 \\
\hline & \multicolumn{2}{|c|}{ Total } & 144 & 72 & 94 & 310 \\
\hline
\end{tabular}

Table 2. The prevalence of malaria and HIV stratified according to age, gender and study site.

\begin{tabular}{cccccccc}
\hline \multirow{2}{*}{ Parameter } & N & \multicolumn{5}{c}{ Malaria } & \multicolumn{3}{c}{ HIV } & \\
\cline { 3 - 7 } & & Positive (\%) & $\chi^{2}$ & p-value & Positive (\%) & $\chi^{2}$ & p-value \\
\hline Age (Month) & & & & & & & \\
$<60$ & 144 & $19(13.2)$ & 9.37 & 0.009 & $7(4.9)$ & 1.151 & 0.562 \\
$60-119$ & 72 & $22(30.6)$ & & & $2(2.8)$ & & \\
$\geq 120$ & 94 & $20(21.3)$ & & & $6(6.4)$ & & \\
Gender & & & & & & \\
M & 174 & $37(21.3)$ & 0.632 & 0.427 & $8(5.8)$ & 0.050 & 0.823 \\
F & 136 & $24(17.6)$ & & & $7(6.3)$ & & \\
Study site & & & & & & \\
Biyem-assi & 99 & $19(19.2)$ & 2.177 & 0.337 & $0(0.0)$ & 7.421 & 0.024 \\
Cite-verte & 130 & $20(15.4)$ & & & $9(6.9)$ & & \\
Efoulan & 81 & $12(14.8)$ & & & $6(7.4)$ & \\
\hline
\end{tabular}




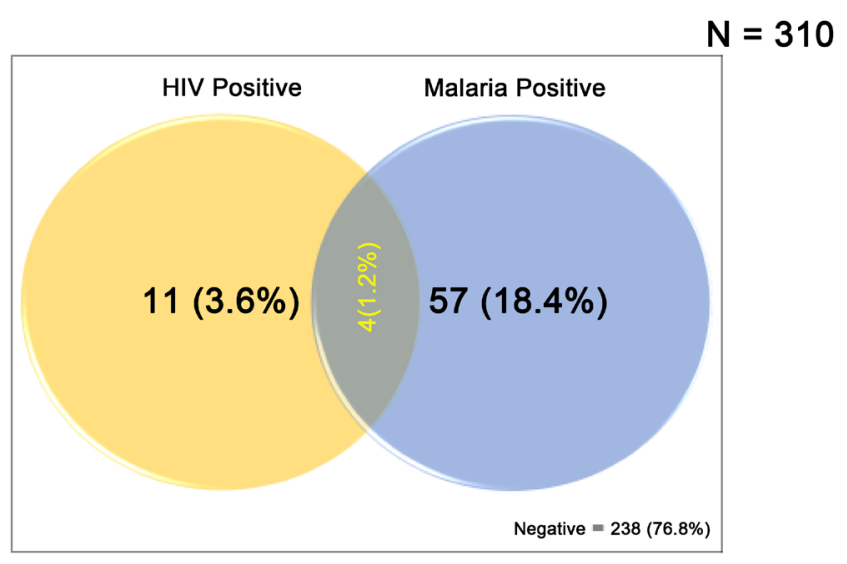

Figure 2. Venn diagram showing the overlap (proportions) of malaria and HIV infection in the study population. Proportions were obtained by dividing the number infected by the total number of participants (310).

\section{Discussion}

The prevalence of malaria in this study was $19.7 \%$. The prevalence observed was lower than the malaria prevalence of $35 \%$ reported in the general population of Yaoundé [22]. This decrease in malaria prevalence in the current study could be attributed to the relentless effort by Cameroon's government to reduce transmission through the distribution of insecticide-treated bed nets (ITNs) to every household in the country as well as the intense sensitization campaign through media [16] [26]. The malaria prevalence in the current study was also lower compared to the national prevalence of $29 \%$ [27].

In the current study, prevalence of malaria was higher in children aged between 60 and 119 months. The observation of a significant association between malaria prevalence and age corroborates studies performed elsewhere [5] [7] [28] [29], and this could be attributed to the playful attitude of children in this age group which exposes them to infective bites of mosquitoes. Conversely, prevalence of malaria in the current study was not observed to be associated with gender or study site. The finding of no association between prevalence of malaria and gender is in conformity with other studies [3] [4] [5] [7].

Plasmodium falciparum was identified as the only species causing malaria in the target population, which is in line with the study by Kwenti et al. [7], but contradictory to the study by Mbenda and Das [30] in which a prevalence of $4 \%$ for $P$. vivax infection was reported in Yaoundé. The differences in the study design may account for this discrepancy; our study targeted mainly children meanwhile theirs targeted adults and children.

The prevalence of HIV in the current study was $4.8 \%$. This prevalence was not very different from the national prevalence of 4.5\% [9], but lower compared to the prevalence of $8.3 \%$ reported in the general population of Yaoundé [10]. Relative to prevalence in the general population of Yaoundé, the lower prevalence of HIV observed in this study could also be attributed to efforts by Cameroon's 
government to control the disease largely through programs to prevent mother-to-child transmission as well as regular sensitization campaigns. There was an association between prevalence of HIV and study site in the current study, being highest in Efoulan (7.4\%). An immediate explanation for this observation was not imminent. However, HIV prevalence in Cameroon has been reported to vary from one location to another and is influenced by the socio-cultural characteristics of the different populations. There was no association between HIV prevalence and age or gender in the current study.

The prevalence of coinfection with malaria and HIV observed in the current study was $1.2 \%$. This finding is similar to the prevalence of $2.24 \%$ reported in Bamenda in the Northwest Region [19]. However, the prevalence of coinfection with malaria and HIV was lower than the $7.3 \%$ and $29.4 \%$ reported by Njunda et al. [16] and Nkuo-Akenji et al. [15] respectively. The difference in the prevalence of coinfection reported in these studies and ours could be attributed to differences in the study designs; our study targeted children in the community meanwhile theirs targeted known HIV patients recruited from HIV treatment facilities.

This study revealed the prevalence of malaria, HIV, and coinfection of malaria with HIV among children in 3 communities in Yaoundé. It has generated data that may be useful in designing control policies. The study is however limited in that participants were recruited from only 3 communities in Yaoundé and the findings may not be generalizable to the entire population of children in Yaoundé. Larger studies will therefore be required in the study area to give a clearer picture.

\section{Conclusion}

In the current study, a prevalence of $19.7 \%, 4.8 \%$, and $1.2 \%$ was observed for malaria, HIV, and coinfection with malaria and HIV respectively. The prevalence of malaria was observed to be associated with age meanwhile the prevalence of HIV was associated with study site, being highest in Efoulan. Plasmodium falciparum was the only species identified as the cause of malaria in the target population. Efforts should be strengthened to control and eventually eliminate malaria and HIV in children in the study area.

\section{Acknowledgements}

Our sincere gratitude goes to all the children who voluntarily took part in this study.

\section{Competing Interests}

The authors declare that they have no competing interests.

\section{Authors' Contributions}

This work was carried out in collaboration between all authors. TEK conceived the study; participated in its design, coordination and data collection; took part 
in the analyses and interpretation; conducted literature search and review; performed the statistical analysis and co-wrote the first draft. EE and BSA participated in the data collection, took part in the analyses and interpretation, conducted the literature search and review and co-wrote the first draft. TDBK conceived, designed and coordinated the study; participated in the statistical analysis; and critically revised the manuscript. All authors read and approved the final manuscript.

\section{References}

[1] World Health Organisation (2016) World Malaria Report 2016. World Health Organisation, Geneva. http://apps.who.int/iris/bitstream/10665/252038/1/9789241511711-eng.pdf?ua=1

[2] World Health Organisation (2015) World Malaria Report 2015. World Health Organisation, Geneva. http://apps.who.int/iris/bitstream/10665/200018/1/9789241565158_eng.pdf?ua $=1$

[3] Njunda, A.L., Fon, S.G., Assob, J.C.N., Nsagha, D.S., Kwenti, T.D.B. and Kwenti, E.T. (2015) Malaria and Intestinal Parasitic Coinfection and Their Contribution to Anaemia in Children in Cameroon. Infectious Diseases of Poverty, 4, 43. https://doi.org/10.1186/s40249-015-0078-5

[4] Kwenti, T.E., Nkume, F.A., Tanjeko, A.T. and Kwenti, T.D.B. (2016) The Effect of Intestinal Parasitic Infection on the Clinical Outcome of Malaria in Coinfected Children in Cameroon. PLoS Neglected Tropical Diseases, 10, Article ID: e0004673. https://doi.org/10.1371/journal.pntd.0004673

[5] Kwenti, T.E., Kwenti, T.D.B., Latz, A., Njunda, L.A. and Nkuo-Akenji, T. (2017) Epidemiological and Clinical Profile of Paediatric Malaria: A Cross Sectional Study Performed on Febrile Children in Five Epidemiological Strata of Malaria in Cameroon. BMC Infectious Diseases, 17, 499. https://doi.org/10.1186/s12879-017-2587-2

[6] World Health Organisation (2010) Cameroon: Epidemiological Profile. World Malaria Report. WHO, Geneva.

[7] Kwenti, T.E., Kwenti, T.D.B., Njunda, L.A., Latz, A., Tufon, K.A. and Nkuo-Akenji, T. (2017) Identification of the Plasmodium Species in Clinical Samples from Children Residing in Five Epidemiological Strata of Malaria in Cameroon. Tropical Medicine and Health, 45, 14. https://doi.org/10.1186/s41182-017-0058-5

[8] UNAIDS (2015a) Fact Sheet 2015. UNAIDS, Geneva. http://www.unaids.org/sites/default/files/media_asset/20150901_FactSheet_2015_en .pdf

[9] UNAIDS (2015b) Cameroon: Epidemiological Fact Sheet on HIV and AIDS. UNAIDS, Geneva.

http://www.unaids.org/en/regionscountries/countries/cameroon/

[10] Kwenti, T.E., Nsagha, D.S., Kwenti, B.D.T. and Njunda, A.L. (2014) Sexual Risk Behaviours among People Living with HIV and Implications for Control in the Northwest Region of Cameroon. World Journal of AIDS, 4, 198-205. https://doi.org/10.4236/wja.2014.42025

[11] Kamya, M.R., Gasasira, A.F., Yeka, A., Bakyaita, N., Nsobya, S.L., Francis, D., et al. (2006) Effect of HIV-1 Infection on Antimalarial Treatment Outcomes in Uganda: A Population-Based Study. Journal of Infectious Disease, 193, 9-15. https://doi.org/10.1086/498577 
[12] Grimwade, K., French, N., Mbatha, D.D., Zungu, D.D., De-Dicoat, M. and Gilks, C.F. (2004) HIV Infection as a Cofactor for Severe Falciparum Malaria in Adults Living in a Region of Unstable Malaria Transmission in South Africa. AIDS, 18, 547-554. https://doi.org/10.1097/00002030-200402200-00023

[13] Cohen, C., Karstaedt, A., Frean, J., Thomas, J., Govender, N., Prentice, E., et al. (2005) Increased Prevalence of Severe Malaria in HIV-Infected Adults in South Africa. Clinical Infection Disease, 41, 1631-1637. https://doi.org/10.1086/498023

[14] Otieno, R.O., Ouma, C., Ong'echa, J.M., Keller, C.C., Were, T., Waindi, E.N., et al. (2006) Increased Severe Anemia in HIV-1-Exposed and HIV-1-Positive Infants and Children during Acute Malaria. AIDS, 20, 275-280. https://doi.org/10.1097/01.aids.0000200533.56490.b7

[15] Nkuo-Akenji, T., Tevoufouet, E.M., Nzang, F., Ngufor, N. and Fon, E. (2008) High Prevalence of HIV and Malaria Co-Infection in Urban Douala, Cameroon. African Journal of AIDS Research, 7, 229-235. https://doi.org/10.2989/AJAR.2008.7.2.8.525

[16] Njunda, A.L., Njumkeng, C., Nsagha, S.D., Assob, J.C.N. and Kwenti, E.T. (2016) The Prevalence of Malaria in People Living with HIV in Yaounde, Cameroon. BMC Public Health, 16, 964. https://doi.org/10.1186/s12889-016-3647-z

[17] Saracino, A., Nacarapa, E.A., da Costa, M.E.A., Martinelli, D., Scacchetti, M., de Oliveira, C., et al. (2012) Prevalence and Clinical Features of HIV and Malaria Coinfection in Hospitalized Adults in Beira, Mozambique. Malaria Journal, 11, 241. https://doi.org/10.1186/1475-2875-11-241

[18] Tay, S.C.K., Badu, K., Mensah, A.A. and Gbedema, S.Y. (2015) The Prevalence of Malaria among HIV Seropositive Individuals and the Impact of the Co-Infection on Their Hemoglobin Levels. Annals of Clinical Microbiology and Antimicrobials, 14, 10. https://doi.org/10.1186/s12941-015-0064-6

[19] Njunda, L.A., Kamga, H.L.F., Nsagha, D.S., Assob, J.C.N. and Kwenti, T.E. (2012) Low Malaria Prevalence in HIV-Positive Patients in Bamenda, Cameroon. Journal of Microbiology Research, 2, 56-59. https://doi.org/10.5923/j.microbiology.20120203.03

[20] World Gazetteer (2013) Cameroon: Largest Cities and Towns and Statistics of Their Population.

[21] Craig, M., Snow, R. and le Sueur, D. (1999) A Climate-Based Distribution Model of Malaria Transmission in Sub-Saharan Africa. Parasitology Today, 15, 105-111. https://doi.org/10.1016/S0169-4758(99)01396-4

[22] van der Kolk, M., Etti T.A., Nimpaye, H., Ngo, N.D., Sauerwein, R. and Eling, W. (2003) Transmission of Plasmodium falciparum in Urban Yaoundé Cameroon Is Seasonal and Age-Dependent. Transactions of the Royal Society of Tropical Medicine and Hygiene, 97, 375-379. https://doi.org/10.1016/S0035-9203(03)90059-9

[23] Swinscow, T.D.V. and Campbell, M.J. (2002) Statistics at Square. 10th Edition, BMJ Books, London.

[24] Njunda, A.L., Assob, N.J.C., Nsagha, S.D., Kamga, F.H.L., Mokenyu, M.D. and Kwenti, E.T. (2013) Comparison of Capillary and Venous Blood Using Blood Film Microscopy in the Detection of Malaria Parasites: A Hospital Based Study. Scientific Journal of Microbiology, 2, 89-94.

[25] Sumbele, I.U.N., Ning, T.R., Bopda, O.S.M. and Nkuo-Akenji, T. (2014) Variation in Malariometric and Red Cell Indices in Children in the Mount Cameroon Area Following Enhanced Malaria Control Measures: Evidence from a Repeated CrossSectional Study. Malaria Journal, 13, 334. https://doi.org/10.1186/1475-2875-13-334 
[26] Kwenti, E.T., Njouom, R., Njunda, L.A. and Kamga, H.L.F. (2011) Comparison of an Immunochromatographic Rapid Strip Test, ELISA and PCR in the Diagnosis of Hepatitis C in HIV Patients in Hospital Settings in Cameroon. Clinical Medicine and Diagnostics, 1, 21-27. https://doi.org/10.5923/j.cmd.20110101.04

[27] Mangham, L.J., Cundill, B., Achonduh, O.A., Ambebila, J.N., Lele, A.K., Metoh, T.N., et al. (2012) Malaria Prevalence and Treatment of Febrile Patients at Health Facilities and Medicine Retailers in Cameroon. Tropical Medicine and International Health, 17, 330-342.

[28] Degarege, A., Legesse, M., Medhin, G., Animut, A. and Erko, B. (2012) Malaria and Related Outcomes in Patients with Intestinal Helminths: A Cross-Sectional Study. BMC Infectious Disease, 12, 291. https://doi.org/10.1186/1471-2334-12-291

[29] Alemu, A., Shiferaw, Y., Ambachew, A. and Hamid, H. (2012) Malaria Helminth Co-Infections and Their Contribution for Anaemia in Febrile Patients Attending Azzezo Health Center, Gondar, Northwest Ethiopia: A Cross Sectional Study. Asian Pacific Journal Tropical Medicine, 5, 803-809.

https://doi.org/10.1016/S1995-7645(12)60147-3

[30] Ngassa, M.H.G. and Das, A. (2014) Molecular Evidence of Plasmodium Vivax Mono and Mixed Malaria Parasite Infections in Duffy-Negative Native Cameroonians. PLoS One, 9, e103262.

https://doi.org/10.1371/journal.pone.0103262

Submit or recommend next manuscript to SCIRP and we will provide best service for you:

Accepting pre-submission inquiries through Email, Facebook, LinkedIn, Twitter, etc. A wide selection of journals (inclusive of 9 subjects, more than 200 journals) Providing 24-hour high-quality service User-friendly online submission system Fair and swift peer-review system Efficient typesetting and proofreading procedure

Display of the result of downloads and visits, as well as the number of cited articles Maximum dissemination of your research work

Submit your manuscript at: http://papersubmission.scirp.org/

Or contactym@scirp.org 